\title{
Violent behaviour and post-traumatic stress disorder in US Iraq and Afghanistan veterans
}

\author{
Eric B. Elbogen, Sally C. Johnson, H. Ryan Wagner, Connor Sullivan, Casey T. Taft and Jean C. Beckham
}

\section{Background}

Violence towards others in the community has been identified as a significant problem for a subset of Iraq and Afghanistan veterans.

\section{Aims}

To investigate the extent to which post-traumatic stress disorder (PTSD) and other risk factors predict future violent behaviour in military veterans.

\section{Method}

A national, multiwave survey enrolling a random sample of all US veterans who served in the military after 11 September 2001 was conducted. A total of 1090 veterans from 50 US states and all military branches completed two survey waves mailed 1 year apart (retention rate $=79 \%$ ).

\section{Results}

Overall, 9\% endorsed engaging in severe violence and $26 \%$ in other physical aggression in the previous year, as measured at Wave 2. Younger age, financial instability, history of violence before military service, higher combat exposure, PTSD, and alcohol misuse at Wave 1 were significantly associated with higher severe violence and other physical aggression in the past year at Wave 2. When combinations of these risk factors were present, predicted probability of violence in veterans rose sharply. Veterans with both PTSD and alcohol misuse had a substantially higher rate of subsequent severe violence (35.9\%) compared with veterans with alcohol misuse without PTSD (10.6\%), PTSD without alcohol misuse $(10.0 \%)$ or neither PTSD nor alcohol misuse (5.3\%). Using multiple regression, we found that veterans with PTSD and without alcohol misuse were not at significantly higher risk of severe violence than veterans with neither PTSD nor alcohol misuse. There was a trend for other physical aggression to be higher in veterans with PTSD without alcohol misuse.

\section{Conclusions}

Co-occurring PTSD and alcohol misuse was associated with a marked increase in violence and aggression in veterans. Compared with veterans with neither PTSD nor alcohol misuse, veterans with PTSD and no alcohol misuse were not significantly more likely to be severely violent and were only marginally more likely to engage in other physical aggression. Attention to cumulative effects of multiple risk factors beyond diagnosis - including demographics, violence history, combat exposure, and veterans' having money to cover basic needs like food, shelter, transportation, and medical care - is crucial for optimising violence risk management.

\section{Declaration of interest}

E.B.E., C.T.T. and J.C.B. are US government employees.
Violence towards others after returning home from military service has been documented to be a significant problem among a subset of veterans in the US, ${ }^{1-3} \mathrm{UK}^{4}{ }^{4}$ Australia $^{5}$ and Canada. ${ }^{6}$ As more men and women re-enter civilian life, there is an increased need to assist clinicians with effective assessment and management of veterans who may be at higher risk of community violence. To date, there has been relatively little direction available to clinicians to help them gauge what level of risk a veteran may pose in the near future. Admission and discharge decisions as well as community treatment planning would be greatly enhanced by research that directly informs, and possibly improves, decision-making and resource allocation in these clinical contexts. ${ }^{7}$

Existing research that has examined violent behaviour towards others among veterans of Iraq and Afghanistan ${ }^{1,2,4,8}$ and previous eras of service ${ }^{9-12}$ provides a starting point, but many questions remain. Empirical studies have found that post-traumatic stress disorder (PTSD) $)^{1,3,7,13}$ and alcohol misuse $e^{1,8,10,11,13}$ are each associated with violence in veterans, but research in this field has predominantly been retrospective in design, with only a few exceptions, ${ }^{4}$ which to a large extent limits data interpretation. ${ }^{7}$ To illustrate, although multiple studies have shown that PTSD in veterans is correlated with aggression in the past, there has been relatively little empirical work examining whether current PTSD statistically predicts subsequent violent behaviour in veterans in the future, and if so, what the extent and nature of this relationship is.
Moreover, the links between PTSD, alcohol misuse and aggression warrant further clarification ${ }^{5,13}$ because although research has shown that PTSD and alcohol misuse each independently relate to aggression towards others in veterans, there has been virtually no attention given to examining violence risk among veterans with comorbid PTSD and alcohol misuse. As PTSD and alcohol misuse often co-occur in returning veterans, ${ }^{14-16}$ it is largely unknown whether veterans with dual disorders pose a higher risk of violence than veterans with PTSD only or with alcohol misuse only, similar to that reported in literature on mental illness and violence in civilian populations. ${ }^{17,18}$

By what mechanism might risk be elevated? Current theory and science of self-dysregulation conceptualises violence and physical aggression as occurring when the strength of impelling forces (those pushing towards action) exceed the strength of the inhibiting forces (those preventing a move towards action). ${ }^{19,20}$ Within this model, if PTSD is viewed as an impelling force and alcohol misuse is considered a disinhibiting force, then the two in tandem could substantially elevate risk for aggression. ${ }^{19-21}$ What is it about PTSD that could impel a veteran towards violence? One answer appears to be hyperarousal symptoms. ${ }^{4,7,10,11,13}$ Anger and irritability, both measureable states, have been identified as empirically related among veterans to be associated with increased violence and aggression. ${ }^{4,7,13}$ In contrast, although alcohol is known to cause disinhibition, most people who drink are not aggressive. This begs the question of when drinking is likely to contribute to aggression. 
Applying this theory to the returning veteran population suggests that veterans with PTSD could feel impelled to act aggressively as a result of anger symptoms but still desist from acting if they are not disinhibited as a result of drinking alcohol. Similarly, veterans misusing alcohol may be disinhibited but be less impelled to act violently if not experiencing PTSD symptoms such as anger and irritability. This relationship may be especially complex for veterans because the military trains soldiers to aggress in a controlled way in the context of war but difficulties caused by PTSD and disinhibition from alcohol misuse could allow trained aggression meant for combat to become less well-controlled. The purpose of this paper is to employ a multiwave data-set of a random sample of US Iraq and Afghanistan veterans to analyse the association of risk factors with subsequent violence and aggression and to test the hypothesis that co-occurring PTSD and alcohol misuse leads to a higher odds of future violence and aggression than PTSD without alcohol misuse or alcohol misuse without PTSD. To our knowledge, this is the first national study of violence in US Iraq and Afghanistan veterans.

\section{Method}

\section{Study design and participants}

The study sample was taken from the National Post-Deployment Adjustment Survey (NPDAS), ${ }^{22}$ which was conducted as part of a US National Institute of Mental Health funded grant to develop risk assessment tools for veterans and was drawn by the US Department of Veterans Affairs (VA) Environmental Epidemiological Service in May 2009. The sample consisted of a random selection of 3000 veterans from a database of over 1 million US military service members who: (a) served after 11 September 2001 in Operation Iraqi Freedom (OIF) or Operation Enduring Freedom (OEF); and (b) either had separated from active duty service or were in the reserves/national guard. The sample was stratified by gender, and female veterans were oversampled to ensure adequate representation; specifically, 1000 female veterans were randomly selected from all female OEF/OIF veterans and 2000 male veterans were selected from all male OEF/OIF veterans.

After obtaining institutional review board approval, we surveyed veterans using Dillman survey methodology ${ }^{23}$ using multiple and varied contacts to maximise response rate. We implemented two waves of data collection 1-year apart involving parallel procedures, and participants were reimbursed after finishing each wave. At Wave 1, participants were first sent an introductory letter regarding the upcoming survey. Four days later, potential participants were sent an invitation by mail, which contained commemorative postage stamps as an incentive and instructions on how to complete a 35-minute confidential internet-based survey. Sixteen days after invitations were mailed, potential participants were sent postcards thanking them for completing the survey or reminding them to do so. Two weeks after postcard mailings, those who had not taken the survey received a paper version with a postage-paid return envelope. Two months after the print survey a final letter was sent encouraging participation and explaining the survey would close the following week.

Wave 1 was conducted July 2009 to April 2010, yielding a 47\% response rate and $56 \%$ cooperation rate. The 'response rate' refers to the number of surveys completed divided by the number of surveys sent out, whereas the 'cooperation rate' refers to the number of surveys completed divided by the number of surveys received by participants (i.e. not returned by mail). ${ }^{23}$ These achieved rates are comparable to, or greater than, that achieved in other national surveys of veterans in the US $S^{15,24,25}$ and $\mathrm{UK}^{26}$ Details can be found elsewhere ${ }^{22}$ regarding generalisability of the sample of $n=1388$ veterans who completed Wave 1 of the NPDAS, describing the proportion of veterans receiving services at VA and non-VA facilities and indicating little difference on age, gender and geographic region between responders $v$. non-responders as well as little difference on available demographic, military and clinical variables between those who took the survey after the first invitation $v$. after subsequent reminders, and between paper $v$. internet survey completers.

At Wave 2, participants were queried exactly 1 year after completing the Wave 1 survey over the period July 2010-April 2011. At conclusion, $n=1090$ veterans completed Wave 2, yielding a $79 \%$ retention rate. The median time lapse between completion of Wave 1 and Wave 2 was 12.8 months. Of the sample, $78 \%$ completed both waves between 12 and 14 months apart. Ninety per cent of the sample completed Waves 1 and 2 between 11 and 15 months apart. Very few were outside this range: less than $1 \%$ took the two surveys 10-11 months apart, 8\% 15-19 months apart, and less than 1\% 19-20 months apart.

In terms of retention, multivariate analyses revealed that younger age and lower income accounted for $4 \%$ of the attrition-related variance at Wave 2; other variables specified below - including PTSD and history of violence - were nonsignificant; presumably, residential stability of younger and less financially able participants as a subgroup affected re-survey efforts. Aside from the latter two measures, attrition analyses did not indicate any substantial bias associated with primary study outcomes. Regarding Wave 2 participation, we would emphasise that no other national studies of the OEF/OIF cohort have attained equivalent rates of retention.

The military branch breakdown of the final sample $(55.21 \%$ army, $19.92 \%$ air force, $14.88 \%$ navy, $9.64 \%$ marines, and $0.35 \%$ coast guard) approximated the composition of the armed forces (48\% army, $22 \%$ air force, $17 \%$ navy, $11 \%$ marines, and $2 \%$ coast guard) at the time of the survey. ${ }^{27}$ Of the veterans sampled, $73 \%$ were White and $48 \%$ in the sample were national guard/reserves, similar to $70 \%$ who were White and $37 \%$ who were national guard/reserves in the military at the time. ${ }^{27}$ The majority of respondents (82\%) had been deployed to Iraq or Afghanistan with a range in time from last deployment of 1-8 years, with a median time of 4 years. The remainder of the sample was comprised of OIF/OEF veterans that were not stationed in either of the two combat theatres. Geographically, the final sample corresponded to known military demographics with the 50 US states, Washington DC, and 4 territories representing in a close approximation to reported military statistics. ${ }^{27}$ To our knowledge, the NPDAS has enrolled one of the most representative samples of US Iraq and Afghanistan veterans to date.

\section{Assessment protocol}

At Wave 1, current PTSD was measured by the Davidson Trauma Scale ${ }^{28}$ using a cut-off score of 48 ; this cut-off point has been shown to provide 0.82 sensitivity and 0.94 specificity with the Structured Clinical Interview for DSM-IV Disorders (SCID) in Iraq and Afghanistan veterans. ${ }^{29}$ Current alcohol misuse was defined positive for veterans attaining a score of 8 or greater on the Alcohol Use Disorder Identification Test (AUDIT). ${ }^{30}$

We selected covariates at Wave 1 based on a review of risk factors in veterans populations, ${ }^{7}$ which included: age, financial stability (defined as having money to cover basic needs such as food, clothes, shelter, medical care, transportation, and social activities per the Quality of Life Interview ${ }^{31}$ ), history of violence (defined by self-report of arrest for a violent crime or engagement in an act of violence towards others prior to military service), and combat exposure (as measured by the Deployment Risk and 
Resilience Inventory ${ }^{32}$ ). We also included gender as it has been shown consistently to have one of the strongest associations with violence in civilian populations and thus would also be relevant to include in analysis. ${ }^{33}$

At Wave 2, community-based violence towards others during the 1 year study period was measured at two levels of severity. Severe violence in the past year was measured by endorsement of specific items on the Conflict Tactics Scale ${ }^{34}$ (i.e. 'Used a knife or gun', 'Beat up the other person' or 'Threatened the other person with a knife or gun') or on the MacArthur Community Violence $\mathrm{Scale}^{35}$ (i.e. 'Did you threaten anyone with a gun or knife or other lethal weapon in your hand?', 'Did you use a knife or fire a gun at anyone?' or 'Did you try to physically force anyone to have sex against his or her will?'). Other physical aggression in the past year was assessed using additional items from these two scales addressing less lethal/serious physically aggressive acts (i.e. kicking, slapping, using fists, getting into fights).

Definitions are consistent with operationalisation of severe violence and other physical aggression in the MacArthur Violence Risk Assessment Study. ${ }^{33}$ Research has shown that veterans' self-reports of violence are related to arrest records for violent crimes ${ }^{4,36}$ and that veterans' self-report of violence substantially agrees with collateral informants. ${ }^{37}$ This is consistent with civilian studies of violent behaviour supporting the validity of self-report for measuring violent behaviour as used in the current study. ${ }^{17,18}$

\section{Statistical analyses}

SAS 9.2 for Windows was used for statistical analyses. Women were oversampled to comprise $33 \%$ of the survey sample but constituted $15.6 \%$ of the military at the time of data collection. ${ }^{27}$ Data were weighted to reflect the latter proportion, rendering a weight- adjusted $n=866$. Chi-squared analyses were used to analyse associations between risk factors at Wave 1 and severe violence and other physical aggression at Wave 2 .

Multiple logistic regression was used to analyse associations between risk factors at Wave 1 and severe violence and other physical aggression at Wave 2. Model validity was assessed using bootstrapped bias estimates (1000 replications) to derive comparisons between model-based coefficients and corresponding bootstrap estimates. Models were also re-estimated: (a) using the subset of the $82 \%$ of veterans actually deployed in Iraq and/or Afghanistan to investigate for putative effects of theatre and time since last deployment; and (b) adding 'time between waves 1 and $2^{\prime}$ as an additional variable to modelling.

We explored factors associated with alcohol misuse in a subset of veterans meeting criteria for PTSD, focusing on the association between violence and PTSD symptoms. Predicted probabilities for subsequent severe violence measured at Wave 2 were estimated using a measure of multiple risk factors measured at Wave 1 in order to ascertain whether there were cumulative effects of factors on outcomes.

\section{Results}

\section{Sample characteristics}

At Wave 1, 18\% of respondents met criteria for probable PTSD and $24 \%$ met criteria for alcohol misuse. Of these, $11 \%$ met criteria for PTSD without alcohol misuse, $18 \%$ met criteria for alcohol use only, and 7\% met criteria for both PTSD and alcohol misuse. The median age was 34 years $($ mean $=37$, s.d. $=9.5)$. The age range was 21-92 years, noting that in our random sample of all veterans who served after $9 / 11$, there were 8 participants older than 65 . In the sample, $38 \%$ reported difficulties meeting their basic needs financially, and $8 \%$ reported history of violence prior to enlisting in the military. At Wave 2, the overall prevalence of self-reported severe violence in the past year was $9 \%$ and other physical aggression in the past year was $26 \%$.

\section{Associations between risk factors and violent behaviour}

Table 1 presents the analyses between Wave 1 PTSD and alcohol misuse and Wave 2 severe violence and other physical aggression. Unadjusted chi-squared statistics showed that PTSD was associated with higher rates of severe violence $(20 \%$ v. $6 \%)$ and other physical aggression $(48 \%$ v. $21 \%)$ compared with veterans without PTSD. Correspondingly, unadjusted chi-squared

Table 1 Associations between PTSD, alcohol misuse, and violent behaviour in Iraq and Afghanistan veterans

\begin{tabular}{|c|c|c|c|c|c|c|c|c|c|}
\hline \multirow[b]{2}{*}{ Factor at Wave 1} & \multicolumn{5}{|c|}{ Severe violence } & \multicolumn{4}{|c|}{ Other physical aggression } \\
\hline & $\begin{array}{c}\text { Total } \\
n\end{array}$ & $\begin{array}{l}\text { Severe violence } \\
\text { at Wave } 2, n\end{array}$ & $\%$ & $\chi^{2}$ & $P$ & $\begin{array}{l}\text { Other physical aggression } \\
\text { at Wave } 2, n\end{array}$ & $\%$ & $\chi^{2}$ & $P$ \\
\hline \multicolumn{10}{|l|}{ Meets criteria for PTSD } \\
\hline No & 711 & 46 & 6.41 & 27.34 & $<0.0001$ & 150 & 21.05 & 48.41 & $<0.0001$ \\
\hline Yes & 155 & 30 & 19.52 & & & 75 & 48.06 & & \\
\hline \multicolumn{10}{|l|}{ Meets criteria for alcohol misuse } \\
\hline No & 656 & 39 & 5.97 & 26.21 & $<0.0001$ & 141 & 21.50 & 27.07 & $<0.0001$ \\
\hline Yes & 211 & 36 & 17.43 & & & 83 & 39.54 & & \\
\hline \multicolumn{10}{|l|}{ PTSD without alcohol misuse } \\
\hline Yes & 98 & 10 & 9.96 & 3.27 & 0.0705 & 39 & 40.23 & 23.94 & $<0.0001$ \\
\hline No PTSD or alcohol misuse & 558 & 29 & 5.27 & & & 102 & 18.21 & & \\
\hline \multicolumn{10}{|l|}{ Alcohol misuse without PTSD } \\
\hline Yes & 154 & 16 & 10.57 & 5.64 & 0.0175 & 48 & 31.38 & 12.59 & 0.0004 \\
\hline No PTSD or alcohol misuse & 558 & 29 & 5.27 & & & 102 & 18.21 & & \\
\hline \multicolumn{10}{|l|}{ PTSD + alcohol misuse } \\
\hline Yes & 57 & 21 & 35.88 & 65.15 & $<0.0001$ & 35 & 61.49 & 56.16 & $<0.0001$ \\
\hline No PTSD or alcohol misuse & 558 & 29 & 5.27 & & & 102 & 18.21 & & \\
\hline None & 558 & 29 & 5.27 & 61.91 & $<0.0001$ & 102 & 18.21 & 67.81 & $<0.0001$ \\
\hline PSTD without alcohol misuse & 98 & 10 & 9.96 & & & 39 & 40.23 & & \\
\hline Alcohol misuse without PTSD & 154 & 16 & 10.57 & & & 48 & 31.38 & & \\
\hline PTSD + alcohol misuse & 57 & 21 & 35.88 & & & 35 & 61.49 & & \\
\hline
\end{tabular}


statistics showed that alcohol misuse was associated with higher rates of severe violence $(17 \% v .6 \%)$ and other physical aggression ( $40 \%$ v. $22 \%$ ) compared with veterans without alcohol misuse.

However, veterans with PTSD and no alcohol misuse were not statistically more likely to be severely violent compared with veterans with neither PTSD nor alcohol misuse (10\% v. 5\%), although they were more likely to engage in other physical aggression $(40 \% v .18 \%)$. Alcohol misusers with no PTSD were more likely to be severely violent $(11 \% v .5 \%)$ and engage in other physical aggression $(31 \%$ v. $18 \%)$ than were veterans with neither PTSD nor alcohol misuse. The latter group was significantly less likely to engage in severe violence $(5 \% v .36 \%)$ and other physical aggression $(18 \%$ v. $61 \%)$ compared with veterans with co-occurring PTSD and alcohol misuse, who had the highest rates of both outcomes, as shown at the end of Table 1.

Given this, we ran a formal test of the interactions between PTSD and alcohol misuse on severe violence and other physical aggression. As could be anticipated from the data on the bottom of Table 1 , we found a statistically significant PTSD $\times$ alcohol misuse interaction with respect to severe violence $(F=19.94$, d.f. $=1$, mean square $=1.18, P<0.0001)$ but not with respect to other physical aggression $(F=1.28$, d.f. $=1$, mean square $=0.181$, $P=0.2573)$. Put differently, the combination of PTSD and alcohol misuse had a unique contribution to predicting severe violence at year 2 above their main effects.

Table 2 presents chi-squared analyses of covariates at Wave 1, showing that history of violence before the military, financial instability, younger age and higher combat exposure were significantly related to severe violence and other physical aggression in the next year as measured in Wave 2.

\section{Multivariate models of violent behaviour}

Multivariate logistic regression analyses presented in Table 3 show that severe violence at Wave 2 was associated significantly with lower age, financial instability, history of violence prior to the military, combat exposure and a comorbid diagnosis of PTSD and alcohol use. Non-significant factors were gender, PTSD without alcohol misuse, and alcohol misuse without PTSD. Other physical aggression at Wave 2 was predicted by Wave 1 history of violence before military, combat exposure, financial instability, alcohol misuse without PTSD, and co-occurring PTSD and alcohol misuse. Gender and age were non-significant. There was a trend for PTSD without alcohol misuse to be positively related to other physical aggression at Wave 2.

Models in Table 3 were validated with bootstrap methodologies and showed little evidence of shrinkage in the original estimates, indicating bias estimates for most coefficients less than $2 \%$. Bootstrapping of severe violence showed good model fit, with a mean concordance $=0.86$ (s.d. $=0.001,95 \%$ CI 0.83-0.90). Likewise, bootstrapping of other physical aggression also showed good model fit, with a mean concordance $=0.85$ (s.d. $=0.001,95 \%$ CI $0.82-0.87$ ).

The two models were also re-estimated on a subset restricted to the $82 \%$ of deployed veterans. Results closely approximated those presented in Table 3 except for age which was no longer significant for severe violence. We also re-ran models to include a

\begin{tabular}{|c|c|c|c|c|c|c|c|c|c|}
\hline \multirow[b]{2}{*}{ Factor at Wave 1} & \multirow[b]{2}{*}{$\begin{array}{c}\text { Total } \\
n\end{array}$} & \multicolumn{4}{|c|}{ Severe violence } & \multicolumn{4}{|c|}{ Other physical aggression } \\
\hline & & $\begin{array}{c}\text { Severe violence } \\
\text { at Wave } 2 n\end{array}$ & $\%$ & $\chi^{2}$ & $P$ & $\begin{array}{l}\text { Other physical } \\
\text { aggression at Wave 2, } n\end{array}$ & $\%$ & $\chi^{2}$ & $P$ \\
\hline \multicolumn{10}{|l|}{ Young age } \\
\hline Above median $\geqslant 34$ & 444 & 21 & 4.76 & 18.15 & $<0.0001$ & 89 & 20.04 & 16.20 & $<0.0001$ \\
\hline Below median $<34$ & 423 & 55 & 12.95 & & & 135 & 32.02 & & \\
\hline \multicolumn{10}{|l|}{ Gender } \\
\hline Female & 134 & 11 & 8.10 & 0.09 & 0.7689 & 35 & 26.26 & 0.01 & 0.9153 \\
\hline Male & 732 & 65 & 8.88 & & & 189 & 25.82 & & \\
\hline \multicolumn{10}{|c|}{ History of violence pre-military } \\
\hline No & 799 & 55 & 6.92 & 43.67 & $<0.0001$ & 189 & 23.60 & 28.12 & $<0.0001$ \\
\hline Yes & 67 & 21 & 30.61 & & & 36 & 53.06 & & \\
\hline \multicolumn{10}{|l|}{ High combat exposure } \\
\hline Below median & 441 & 20 & 4.62 & 19.23 & $<0.0001$ & 74 & 16.73 & 39.26 & $<0.0001$ \\
\hline Above median & 425 & 56 & 13.05 & & & 151 & 35.38 & & \\
\hline \multicolumn{10}{|c|}{ Money to cover basic needs } \\
\hline No & 325 & 47 & 14.35 & 20.34 & $<0.0001$ & 125 & 38.36 & 42.16 & $<0.0001$ \\
\hline Yes & 541 & 29 & 5.40 & & & 100 & 18.40 & & \\
\hline
\end{tabular}

\section{Table 3 Multivariate models of severe violence and other physical aggression in Iraq and Afghanistan veterans}

\begin{tabular}{|c|c|c|c|c|c|c|}
\hline \multirow[b]{2}{*}{ Factor at Wave 1} & \multicolumn{3}{|c|}{ Severe violence at Wave 2} & \multicolumn{3}{|c|}{ Other physical aggression at Wave 2} \\
\hline & Odds ratio & $95 \% \mathrm{Cl}$ & $P$ & Odds ratio & $95 \% \mathrm{Cl}$ & $P$ \\
\hline \multicolumn{7}{|l|}{ Covariates } \\
\hline Age & 0.96 & $0.93-0.99$ & 0.0184 & 0.99 & $0.97-1.00$ & 0.0847 \\
\hline Gender & 0.88 & $0.42-1.86$ & 0.7412 & 0.80 & $0.50-1.27$ & 0.3347 \\
\hline History of violence pre-military & 3.95 & $2.05-7.62$ & $<0.0001$ & 2.51 & $1.44-4.37$ & 0.0011 \\
\hline Combat exposure & 1.03 & $1.01-1.05$ & 0.0066 & 1.04 & $1.02-1.05$ & $<0.0001$ \\
\hline Money to cover basic needs & 0.81 & $0.71-0.92$ & 0.0009 & 0.82 & $0.75-0.90$ & $<0.0001$ \\
\hline \multicolumn{7}{|l|}{ PTSD and/or alcohol misuse } \\
\hline PTSD only & 0.91 & $0.39-2.16$ & 0.8249 & 1.63 & $0.98-2.70$ & 0.0583 \\
\hline Alcohol misuse only & 1.32 & $0.67-2.62$ & 0.4197 & 1.55 & $1.00-2.39$ & 0.0484 \\
\hline PTSD + alcohol misuse & 4.09 & $1.91-8.77$ & 0.0003 & 3.45 & $1.83-6.50$ & 0.0001 \\
\hline Reference group: neither PTSD nor alcohol misuse & \multicolumn{3}{|c|}{$R^{2}=0.22, \chi^{2}=94.91$, d.f. $=8, P<0.0001$} & \multicolumn{3}{|c|}{$R^{2}=0.18, \chi^{2}=126.89$, d.f. $=8, P<0.0001$} \\
\hline
\end{tabular}




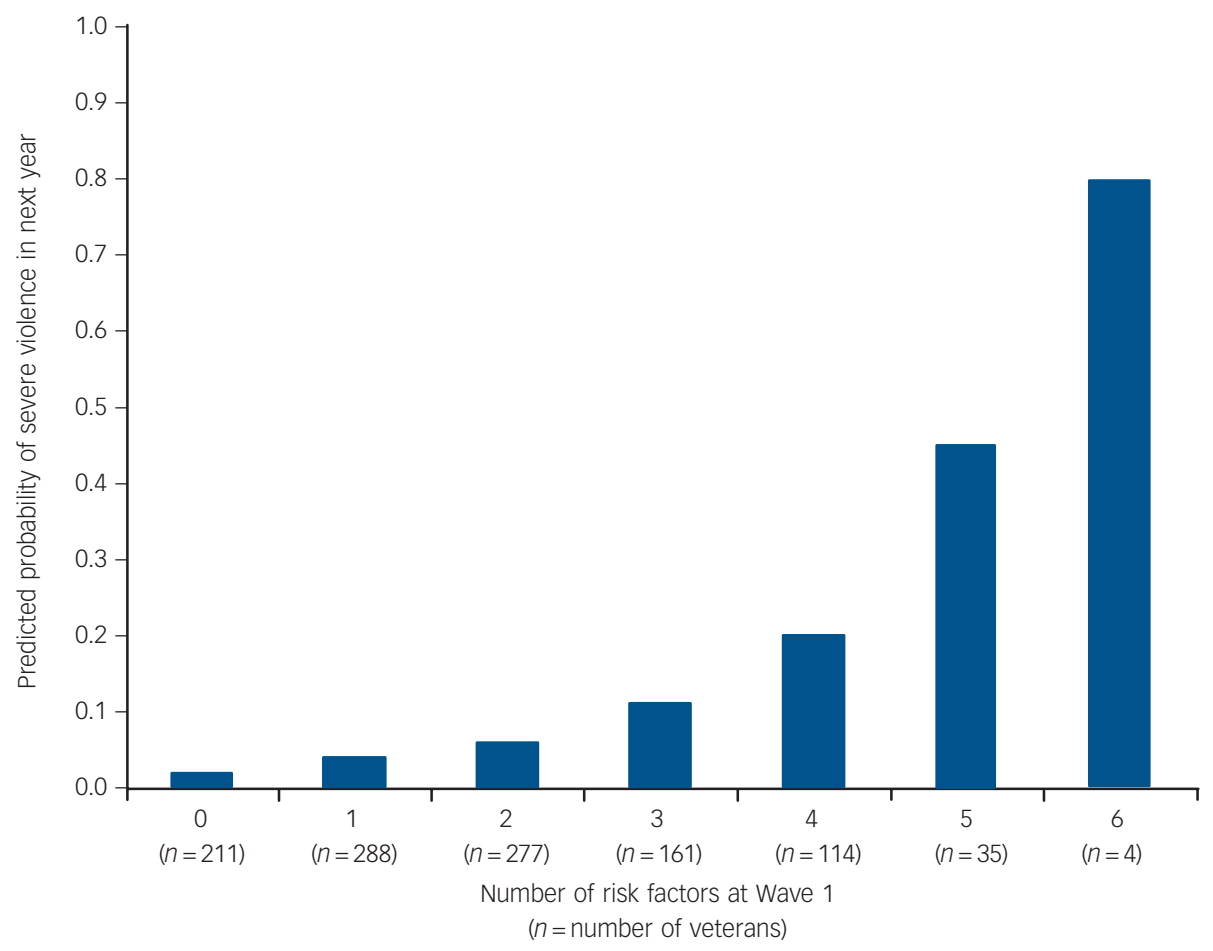

Fig. 1 Predicted probability of violence in the next year as a function of cumulative risk factors at Wave 1.

Risk factors included: young age (below median of 34 years), not meeting basic needs, history of violence before military service, higher combat exposure (above median), post-traumatic stress disorder, and alcohol misuse.

variable connoting number of days between Wave 1 and Wave 2 . We found that the overall fit of both multivariate models were not significantly altered by the addition of this variable and that risk factors associated with future violence and other physical aggression in Table 3 retained the same magnitude of statistical significance when time between waves was added into regression analyses.

Another model was estimated that attempted to identify factors that might differentiate between veterans with co-occurring PTSD and alcohol misuse $v$. those with PTSD only. Results showed that alcohol misuse among veterans with PTSD was significantly associated with specific PTSD symptoms: feeling numb/being unable to have sad or loving feelings (odds ratio $(\mathrm{OR})=1.510$, $P=0.0054)$ and anger/irritability $(\mathrm{OR}=1.358, P=0.0470)$. No other PTSD symptoms or general risk factors were associated with increased alcohol misuse.

The increase in violence risk associated with co-occurring diagnoses of PTSD and alcohol misuse suggests that the effect of risk factors may be cumulative. To test this possibility, risk factors identified above were combined and modelled using logistic regression procedures. Results are presented in Fig. 1 showing the predicted probability of severe violence at Wave 2 as a function of cumulative risk factors at Wave 1. As shown in the graph, the predicted probability of severe violence increases with cumulative risk. Thus, veterans with no risk factors at Wave 1 had a very low probability of severe violence in the following year (0.02); this probability increases with the cumulative increase in risk to a dramatically high maximum risk of 0.80 among veterans endorsing all six risk factors.

\section{Discussion}

Using a random sample of US Iraq and Afghanistan veterans, the current study enhances understanding of how PTSD is related to violence and physical aggression. To our knowledge, this is the first national multiwave study examining empirically the association between PTSD and subsequent violence in US Iraq and Afghanistan veterans. Although previous studies have shown a relationship, ${ }^{1,3,4,7,13}$ and PTSD is often touted as a key contributor to violence in veterans, our current findings reveal a more nuanced relationship.

\section{Associations between PTSD, aggression and violent behaviour}

On the one hand, the data provide some evidence that PTSD is associated with elevated risk of violence and aggression in veterans. Unadjusted chi-squared analyses show that veterans with PTSD were more likely to commit severe violence in the next year compared with veterans without PTSD $(20 \%$ v. $6 \%)$ and were more likely to be involved in other physical aggression (48\% $v$. $21 \%)$. Post-traumatic stress disorder without alcohol misuse came close to showing a significant relationship to elevated risk of other physical aggression in multiple regression analyses. Because veterans with PTSD and alcohol misuse had higher rates of violence than veterans with only alcohol misuse, PTSD remains an important factor in the study of violence and aggression in veterans.

On the other hand, the data suggest that PTSD may play a less direct and somewhat weaker role in violence by veterans than is commonly perceived. Veterans with PTSD who did not misuse alcohol reported both less anger and irritability and were not significantly more likely to engage in severe violence compared with veterans with neither PTSD nor alcohol misuse, and were $72 \%$ less likely to report severe violence in the next year than their counterparts with PTSD who misused alcohol. In this national random sample, most veterans with PTSD did not report severe violence. The current results thus highlight that better understanding of the relationship between PTSD and violence 
requires consideration of co-occurring conditions, specific PTSD symptoms and severity of violence.

\section{Understanding violence in veterans with co-occurring PTSD and alcohol misuse}

These data signal that a subset of veterans, specifically those with co-occurring PTSD and alcohol misuse, is at substantially higher risk of violence when compared with other veterans. Of all veterans meeting criteria for current PTSD in this sample, 37\% also met criteria for current alcohol misuse. As shown in Table 1 , a higher risk of severe violence does not result merely from the added effects of PTSD and alcohol misuse. This is consistent with the previously discussed conceptual model of violence which identifies the critical importance of understanding the possible relevance of impelling and inhibiting forces. ${ }^{20,21}$

Several potential pathways exist in which PTSD and alcohol misuse could increase risk of violence. Use of alcohol could exacerbate PTSD hyperarousal symptoms such as anger/irritability. This was suggested by previous research, ${ }^{10,13}$ and is consistent with current findings that anger and irritability were greater among veterans with PTSD and alcohol misuse. Conversely, higher PTSD symptoms could lead to increasing use of alcohol as a form of self-medication which in turn may increase disinhibition and impulsivity. Both pathways could occur simultaneously and reinforce one another, creating a cycle of increased risk. The current findings underscore the possible benefit of future research focusing on better understanding of the interrelationships between PTSD symptoms, alcohol misuse and violence in veterans. ${ }^{10,13,38}$

\section{Treating violence in veterans with co-occurring PTSD and alcohol misuse}

There are challenges for clinicians addressing violence in this at-risk group of veterans. At the individual level, studies have identified the presence of barriers to care among veterans with mental health problems ${ }^{15,16}$ and in particular have shown that veterans with co-occurring PTSD and alcohol misuse are among those with the highest level of perceived barriers to care and least likely to recognise that mental health treatment will be helpful to them. ${ }^{22}$ Additional studies show that veterans with alcohol use disorders show relatively low rates of treatment utilisation. ${ }^{14,22}$ As such, policy makers should be alerted that alcohol misuse needs to be considered and targeted in campaigns to promote mental healthcare use in veterans. Likewise, clinicians should be aware that insight into the relationship between one's mental health condition and alcohol misuse needs to be addressed in a subset of veterans at high risk of violence.

On a systems level, there are also challenges for integrating mental health and alcohol misuse treatment for veterans. In the USA, although VA medical centres provide assessment and treatment for PTSD and alcohol misuse, integrating services for veterans with co-occurring disorders can be difficult. Recent VA policies are aimed at better coordination of treatment, but training clinicians to competently and consistently assess for and treat both PTSD and alcohol misuse is likely to take time. Currently, there exist no violence risk assessment tools designed specifically for military populations but clinicians can use risk assessment tools developed for civilians with the caveat of limited research at this time. ${ }^{7}$ Questions also remain as to how to best address risk management in the context of integrated treatment.

Recent research supports that veterans with aggression do utilise treatment; unfortunately, reduction in aggressive behaviour among Iraq and Afghanistan veterans has not been shown to be related to the number of out-patient mental health visits or to first-line recommended psychotropic medications. These studies underscore the need for more investigation into how much and what type of treatment may be most effective in reducing violence and for more research targeting the study of integrated interventions aimed at establishing optimal treatment outcomes. Better coordination of care between PTSD and alcohol misuse clinics could help veterans at highest risk get the services they need to function more safely in the community. Standardised and repeated assessment of PTSD symptom status and alcohol misuse patterns and severity could encourage ongoing attention to documentation of these pertinent violence risk factors.

\section{Association of other risk factors and reduction of violent behaviour in veterans}

The findings also support that risk factors beyond PTSD and alcohol misuse are important in understanding violence and physical aggression in veterans. Other risk factors affecting levels of violence included younger age, combat exposure, financial instability and history of violence before military service, and are consistent with those found in previous research. ${ }^{1,3,4,13,36}$ The complexity of interactions of these factors is shown in Fig. 1. For example, meeting criteria for PTSD or having higher combat exposure substantially elevated probability of violence when other risk factors (e.g. history of violence prior to military) were present.

Moreover, PTSD, alcohol misuse and meeting basic needs (e.g. having enough money to cover food, shelter, clothes, medical care, transportation, social activities) are dynamic risk factors and can be changed. If treatment providers help veterans address these factors clinically, there is a good likelihood of reducing the odds of violence. Specifically, the current data suggest that the various methods that armed forces use to attempt to proactively address the potential psychological impact of combat experiences or traumatic exposure, such as BattleMind ${ }^{39}$ or Master Resiliency Training ${ }^{40}$ in the USA, the Decompression Programme and CAN OSIS in Canada, ${ }^{41}$ BattleSMART in Australia ${ }^{42}$ and the TRiM programme in the $\mathrm{UK}^{43}$ may help reduce violence risk if they are successful in decreasing PTSD symptoms and alcohol misuse. Figure 1 illustrates that the cumulative effect of risk factors is more important for clinicians to consider than any individual risk factor when determining risk of violence.

\section{Limitations}

Violence and physical aggression are serious problems for a subset of veterans. The benefits from this research appear to outweigh any limitations. Nonetheless, self-report leaves the possibility of underreporting behaviours relevant to factors (e.g. PTSD) and outcomes (e.g. violence). To address this, standardised definitions and standardized measures to increase internal validity of findings were used. Study rates of PTSD comport with national prevalence in US Iraq and Afghanistan veterans, although are higher than rates in the $\mathrm{UK},{ }^{14-16}$ which speaks against underreporting. Rates of violence found also were generally consistent with extant literature on veterans and violence., ${ }^{3,7}$

Not every possible candidate risk factor or covariate was examined in this study. Other possible pathways to violence in veterans with PTSD in addition to alcohol misuse, such as use of illegal drugs, negative affect, lower socioeconomic status, and state $v$. trait anger, all warrant further investigation, particularly given the need to identify effective treatment interventions in at-risk veterans. It is possible that some veterans were in treatment for anger and aggression but this was not measured or factored 
into analyses in this study; future research is needed to examine effects of treatment on violence in veterans. Study of classes of victims of violence was not addressed. Future research should be directed as examining correlates of family $v$. stranger violence, with the goal of helping to develop best practise interventions to prevent violence in veterans. This study did not identify an association of gender with violence in veterans, and is in line with past research ${ }^{7}$ but further investigation remains pertinent given the increasing numbers of women veterans over the past two decades.

Although it is difficult to ensure perfect sample representativeness, a number of steps were taken to increase generalisability and external validity. These included a strategy of random sampling of all US veterans who served post $9 / 11$, designing to achieve relatively high response and retention rates, and assessing for similarity between survey sample and actual military on ethnicity, branch and geography. Previous research on violence in veterans has primarily enrolled samples from VA facilities only or from an individual branch of the US military., ${ }^{3,7}$ This national study including VA and non-VA veterans who served across all the different US military branches was designed to help increase the external validity of knowledge gained regarding violent and aggressive behaviour in veterans. ${ }^{4,12}$

\section{Implications}

The current findings provide a context for understanding violent behaviour in US veterans, a subset of whom appeared to be at higher violence risk, consistent with recent findings in the UK. ${ }^{4}$ The data demonstrated that PTSD had some association with violence but it was co-occurrence of PTSD and alcohol misuse that was particularly associated with dramatically increased odds of violent behaviour perpetrated by veterans. It is hoped that results from this study not only contribute to continued international research on this subject, but also inform clinical efforts to more accurately assess veterans' risks for violence and assist in the development of safety and risk reduction plans to ensure better and safer veterans' adjustment into their communities.

Eric B. Elbogen, PhD, Department of Psychiatry, Forensic Psychiatry Program and Clinic, University of North Carolina - Chapel Hill School of Medicine, Chapel Hill, North Carolina, and Mid-Atlantic Mental IIIness Research, Education, and Clinical Center (MIRECC), Durham VA Medical Center, Durham, North Carolina; Sally C. Johnson, MD, Department of Psychiatry, Forensic Psychiatry Program and Clinic, University of North Carolina - Chapel Hill School of Medicine, Chapel Hill, North Carolina; H. Ryan Wagner, PhD, MIRECC, Durham VA Medical Center, Durham, North H. Ryan Wagner, PhD, MIRECC, Durham VA Medical Center, Durham, North
Carolina, and Department of Psychiatry, Duke University School of Medicine, Durham, North Carolina; Connor Sullivan, BA, Department of Psychiatry, Forensic Psychiatry Program and Clinic, University of North Carolina - Chapel Hill School of Medicine, Chapel Hill, North Carolina; Casey T. Taft, PhD, Psychology Service, VA National Center for PTSD, VA Boston Healthcare, Boston, Massachusetts, and Department of Psychiatry, Boston University School of Medicine, Boston, Massachusetts; Jean C. Beckham, PhD, MIRECC, Durham VA Medical Center, Durham, North Carolina, and Department of Psychiatry, Duke University School of Medicine, Durham North Carolina, USA

Correspondence: Eric B. Elbogen, University of North Carolina - Chapel Hill, Box 7160, Chapel Hill, NC 27599, USA. Email: eric.elbogen@unc.edu

First received 2 Jul 2013, final revision 30 Oct 2013, accepted 7 Nov 2013

\section{Funding}

The US National Institute of Mental Health (NIMH) funded this project. The US Department of Veterans Affairs provided infrastructure to conduct the project. The authors' work on this manuscript was independent of the US NIMH and US Department of Veterans Affairs, which had no role in the analysis, interpretation or decision to submit this research report. Preparation of this manuscript was supported by the NIMH (R01MH080988), the Office for Preparation of this manuscript was supported by the NIMH (R01MH080988), the Office for
Research and Development Clinical science and Health Services, Department of Veterans Affairs, and the Mid-Atlantic Mental Illness Research, Education and Clinical Center.

\section{Acknowledgements}

The authors extend their sincere thanks to the participants who volunteered for this study. We also thank Dr Charles Hoge and Dr Matt Huss for comments on an earlier draft of this manuscript. The views expressed in this article are those of the authors and do not necessarily represent the views of the US Department of Veterans Affairs or the National Institutes of Health.

\section{References}

1 Jakupcak M, Conybeare D, Phelps L, Hunt S, Holmes HA, Felker B, et al. Anger, hostility, and aggression among Iraq and Afghanistan war veterans reporting PTSD and subthreshold PTSD. J Trauma Stress 2007; 20: 945-54.

2 Thomas JL, Wilk JE, Riviere LA, McGurk D, Castro CA, Hoge CW. Prevalence of mental health problems and functional impairment among Active Component and National Guard soldiers 3 and 12 months following combat in Iraq. Arch Gen Psychiatry 2010; 67: 614-23.

3 Marshall AD, Panuzio J, Taft CT. Intimate partner violence among military veterans and active duty servicemen. Clin Psychol Rev 2005; 25: 862-76.

4 MacManus D, Dean K, Jones M, Rona RJ, Greenberg N, Hull L, et al. Violent offending by UK military personnel deployed to Iraq and Afghanistan: a data linkage cohort study. Lancet 2013; 381: 907-17.

5 Forbes D, Bryant RA. When the violence of war comes home. Lancet 2013; 381: 883-4.

6 Jones AD. Intimate partner violence in military couples: a review of the literature. Aggress Violent Behav 2012; 17: 147-57.

7 Elbogen EB, Fuller S, Johnson SC, Brooks S, Kinneer P, Calhoun PS, et al. Improving risk assessment of violence among military veterans: an evidence-based approach for clinical decision-making. Clin Psychol Rev 2010; 30: 595-607.

8 Millikan AM, Bell MR, Gallaway MS, Lagana MT, Cox AL, Sweda MG. An epidemiologic investigation of homicides at Fort Carson, Colorado: summary of findings. Mil Med 2012; 177: 404-11.

9 Orcutt HK, King LA, King DW. Male-perpetrated violence among Vietnam veteran couples: relationships with veteran's early life characteristics, trauma history, and PTSD symptomatology. J Trauma Stress 2003; 16 381-90.

10 Savarese VW, Suvak MK, King LA, King DW. Relationships among alcohol use, hyperarousal, and marital abuse and violence in Vietnam veterans. J Trauma Stress 2001; 14: 717-32.

11 McFall M, Fontana A, Raskind M, Rosenheck R. Analysis of violent behavior in Vietnam combat veteran psychiatric inpatients with posttraumatic stress disorder. J Trauma Stress 1999; 12: 501-17.

12 Taft CT, Pless AP, Stalans LJ, Koenen KC, King LA, King DW. Risk factors for partner violence among a national sample of combat veterans. J Consult Clin Psychol 2005; 73: 151-9.

13 Taft CT, Kaloupek DG, Schumm JA, Marshall AD, Panuzio J, King DW, et al Posttraumatic stress disorder symptoms, physiological reactivity, alcohol problems, and aggression among military veterans. J Abnorm Psychol 2007; 116: $498-507$.

14 Iversen AC, van Staden L, Hughes JH, Browne T, Hull L, Hall J, et al. The prevalence of common mental disorders and PTSD in the UK military: using data from a clinical interview-based study. BMC Psychiatry 2009; 9: 68.

15 Tanielian T, Jaycox L. Invisible Wounds of War: Psychological and Cognitive Injuries, Their Consequences, and Services to Assist Recovery. RAND Corporation, 2008

16 Hoge CW, Castro C, Messer S, McGurk D, Cotting D, Koffman R. Combat duty in Iraq and Afghanistan: mental health problems and barriers to care. $N$ Engl J Med 2004; 351: 13-22

17 Swanson JW, Holzer CE. Violence and ECA data. Hosp Community Psychiatry 1991; 42: 954-5.

18 Steadman HJ, Mulvey EP, Monahan J, Robbins PC, Appelbaum PS, Grisso T, et al. Violence by people discharged from acute psychiatric inpatient facilities and by others in the same neighborhoods. Arch Gen Psychiatry 1998; 55: 393-401.

19 Denson TF, DeWall CN, Finkel EJ. Self-control and aggression. Curr Dir Psychol Sci 2012; 21: 20-5.

20 Finkel EJ. Impelling and inhibiting forces in the perpetration of intimate partner violence. Rev Gen Psychol 2007; 11: 193-207.

21 Taft CT, Kachadourian LK, Suvak MK, Pinto LA, Miller MM, Knight JA, et al. Examining impelling and disinhibiting factors for intimate partner violence in veterans. J Fam Psychol 2012; 26: 285-9. 
22 Elbogen EB, Wagner HR, Johnson SC, Kinneer P, Kang H, Vasterling JJ, et al. Are Iraq and Afghanistan veterans using mental health services? New data from a national random sample survey. Psychiatr Serv 2013; 64: 134-41.

23 Dillman DA, Smyth JD, Christian LM. Internet, Mail, and Mixed-Mode Surveys: The Tailored Design Method (3rd edn). John Wiley, 2009.

24 Vogt D, Vaughn R, Glickman ME, Schultz M, Drainoni ML, Elwy R, et al. Gender differences in combat-related stressors and their association with postdeployment mental health in a nationally representative sample of U.S OEF/OIF veterans. J Abnorm Psychol 2011; 120: 797-806.

25 Beckham JC, Becker ME, Hamlett-Berry KW, Drury PD, Kang HK, Wiley MT, et al. Preliminary findings from a clinical demonstration project for veterans returning from Iraq or Afghanistan. Mil Med 2008; 173: 448-51.

26 Hotopf M, Hull L, Fear NT, Browne T, Horn O, Iversen A, et al. The health of UK military personnel who deployed to the 2003 Iraq war: a cohort study. Lancet 2006; 367: 1731-41.

27 Defense Equal Opportunity Management Institute. FY2009 Annual Demographic Profile of Military Members in the Department of Defense and U.S. Coast Guard. Defense Equal Opportunity Management Institute, 2010.

28 Davidson JRT, Book SW, Colket JT, Tupler LA, Roth S, David D, et al. Assessment of a new self-rating scale for posttraumatic stress disorder. Psychol Med 1997; 27: 153-60.

29 McDonald SD, Beckham JC, Morey RA, Calhoun PS. The validity and diagnostic efficiency of the Davidson Trauma Scale in military veterans who have served since September 11th, 2001. J Anxiety Disord 2009; 23 247-55.

30 Bradley KA, Bush KR. Screening for problem drinking: comparison of CAGE and AUDIT. Ambulatory Care Quality Improvement Project (ACQUIP). Alcohol Use Disorders Identification Test. J Gen Intern Med 1998; 13: 379-88.

31 Lehman AF. A quality of life interview for the chronically mentally ill. Eval Program Plan 1988; 11: 51-62.

32 King DW, King LA, Vogt DS. Manual for the Deployment Risk and Resilience Inventory (DRRI): A Collection of Measures for Studying Deployment Related Experiences of Military Veterans. National Center for PTSD, 2003.
33 Monahan J, Steadman HJ. Violence and Mental Disorder: Developments in Risk Assessment. University of Chicago Press, 1994.

34 Straus MA. Measuring intrafamily conflict and violence: the Conflict Tactics Scales. J Marriage Fam 1979; 41: 75-88.

35 Steadman HJ, Silver E, Monahan J, Appelbaum PS, Robbins PC, Mulvey EP, et al. A classification tree approach to the development of actuarial violence risk assessment tools. Law Hum Behav 2000; 24: 83-100.

36 MacManus D, Dean K, Al Bakir M, Iversen AC, Hull L, Fahy T, et al. Violent behaviour in UK military personnel returning home after deployment. Psychol Med 2012; 42: 1663-73.

37 Elbogen EB, Johnson SC, Newton VM, Fuller SR, Wagner HR, Beckham JC. Self-report and longitudinal predictors of violence in Iraq and Afghanistan veterans. J Nerv Ment Dis 2013; 201: 872-6.

38 Stappenbeck CA, Hellmuth JC, Simpson T, Jakupcak M. The effects of alcohol problems, PTSD, and combat exposure on nonphysical and physical aggression among Iraq and Afghanistan war veterans. Psychol Trauma 2013; 1 Apr ePub ahead of print (doi: 10.1037/a0031468).

39 Adler AB, Bliese PD, McGurk D, Hoge CW, Castro CA. Battlemind debriefing and battlemind training as early interventions with soldiers returning from iraq: randomization by platoon. J Consult Clin Psychol 2009; 77: 928-40.

40 Reivich KJ, Seligman MEP, McBride S. Master resilience training in the U.S Army. Am Psychol 2011; 66: 25-34

41 Garber BG, Zamorski MA. Evaluation of a third-location decompression program for Canadian forces members returning from Afghanistan. Mil Med 2012: 177: 397-403.

42 Cohn A, Crane MF, Hodson SE. Psychological Resilience Training in the Australian Defence Force. Nova Scotia Publishers, 2011.

43 Greenberg N, Langston V, Iversen AC, Wessely S. The acceptability of 'Trauma Risk Management' within the UK armed forces. Occup Med (Lond) 2011; 61: 184-9.

The 1605 Gunpowder Plot, much-quoted sayings, betrayals and killings infest Shakespeare's shortest tragedy, best played without an interval. Macbeth and his Lady who are throneward-bound murder King Duncan, Banquo (whose ghost returns), Macduff's wife and children. Witches and prophecies enthral Macbeth, Lady $\mathrm{M}$ goes mad with hand washing: 'canst thou not minister to a mind diseased?', he asks a physician. There are hallucinations - 'is this a dagger?', stones that 'prate' - delusions of invincibility and haunting lines on life's meaninglessness that reflect contemporary witchcraft angst and doubts. A demonic blood fest about regime change, in post-Fawkesian Britain, Macbeth is theatrical fireworks. 